\title{
Estudio Bioestratigráfico del Paleozoico Superior del Anticlinorio de Huayacocotla en la Sierra Madre Oriental
}

Pérez Ramos, Olivia *

\section{INTRODUCCION}

Varios estudios geológico-estratigráficos se han desarrollado en el Anticlinorio de Huayacocotla, entre los que destacan los realizados por Martínez P. (1962), Reyes O. (1962), Vollbrechtshausen U. (1963) y Carrillo Bravo (1965).

El presente estudio se apoya principalmente en el trabajo de Carrillo Bravo (op. cit.) y tiene como objetivo la bioestratigrafía de los sedimentos paleozoicos y su interpretación ambiental. Para el propósito de este trabajo, se escogió la sección correspondiente al Rio Tlahualompa (Fig. I), la cual se consideró la más completa y representativa en cuanto al número de afloramientos. En el laboratorio se trató de establecer las microfácies características del área y el probable origen de los sedimentos arcillo-arenosos.

\section{ESTRATIGRAFIA}

El Anticlinorio de Huayacocotla(Erben, 1956), representa una gran estructura plegada de la Sierra Madre Oriental. En su núcleo se presentan rocas del basamento. Esta área se inicia en la región de Tenango de San Agustín, Hgo. y termina al NE de Zacatlán, Pue., con una orientación NW-SE, atrave- sando parte de los estados de Hidalgo y Veracruz hasta el norte del Estado de Puebla.

Estudios anteriores en esta región reportan una secuencia de rocas intensamente deformadas y falladas que abarcan desde el Precámbrico hasta el Cenozoico; ésta comprende rocas ígneas extrusivas e intrusivas, las primeras en proporciones mayores que las últimas, rocas metamórficas que incluyen gneis, esquisto y metaconglomerado y rocas sedimentarias, destacando principalmente las detríticas como son conglomerado, arenisca y lutita, y en menor abundancia sedimentos carbonatados como caliza y dolomía.

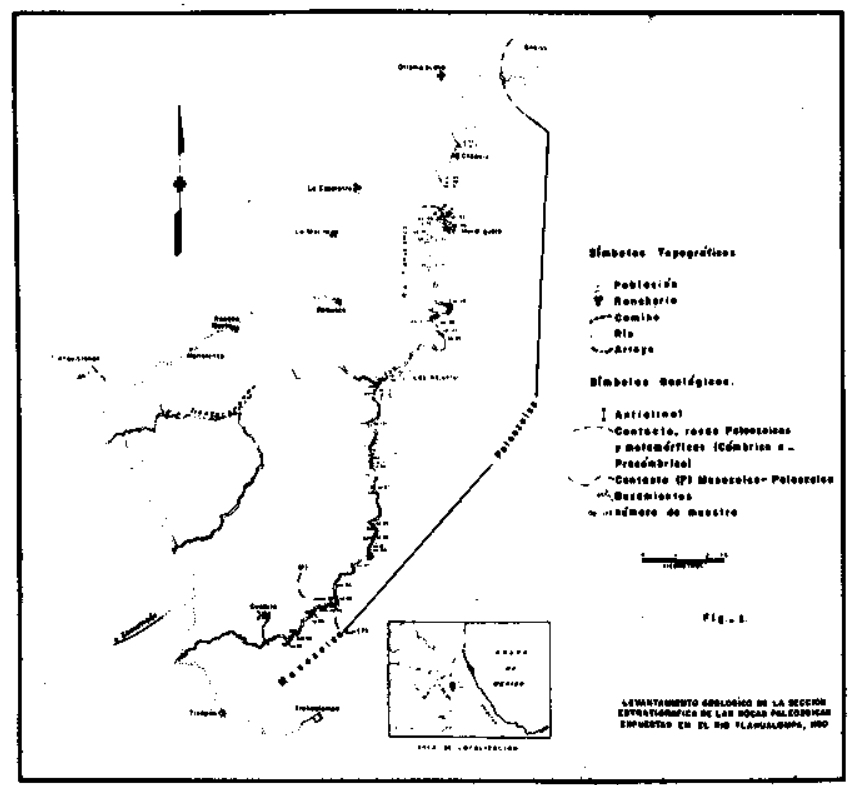


El área en estudio correspondiente a la sección Rio Tlahualompa en el Anticlinorio de Huayacocotla, se encuentra localizada en la parte oriental del Estado de Hidalgo, al NE de las poblaciones de Zacualtipán y Tianguistengo (Fig. I). En esta sección, Carrillo Bravo (op. cit.) describe sedimentos arcilloarenosos del Pérmico Inferior (Leonardiano-Wolfcampiano) perteneciente a la Formación Guacamaya (Carrillo, 1961), con un espesor de más de 2000 $\mathrm{m}$, los cuales el mismo autor correlaciona con los sedimentos paleozoicos que afloran en el Cañón de la Peregrina, Cd. Victoria, Tamps., en donde describe la localidad tipo.

En la sección del Río Tlahualompa los 2 géneros índice de edad Wolfcampiano-Leonardiano) Schwagerina sp. y Triticites sp., determinados por cl Dr. Marlynd Nestell de la Universidad de Texas en Arlington (comunicación oral), coinciden con los nombrados por Carrillo en el área en estudio.

La base de la secuencia paleozoica en el Anticlinorio de Huayacocotla está constituida por rocas metamórficas que se correlacionan con el Gneis Huiznopala de Fries y Rincón Orta (1965) de edad precámbrica tardía.

Sección Estratigraficg Rio Tlahualompo, Hgo.

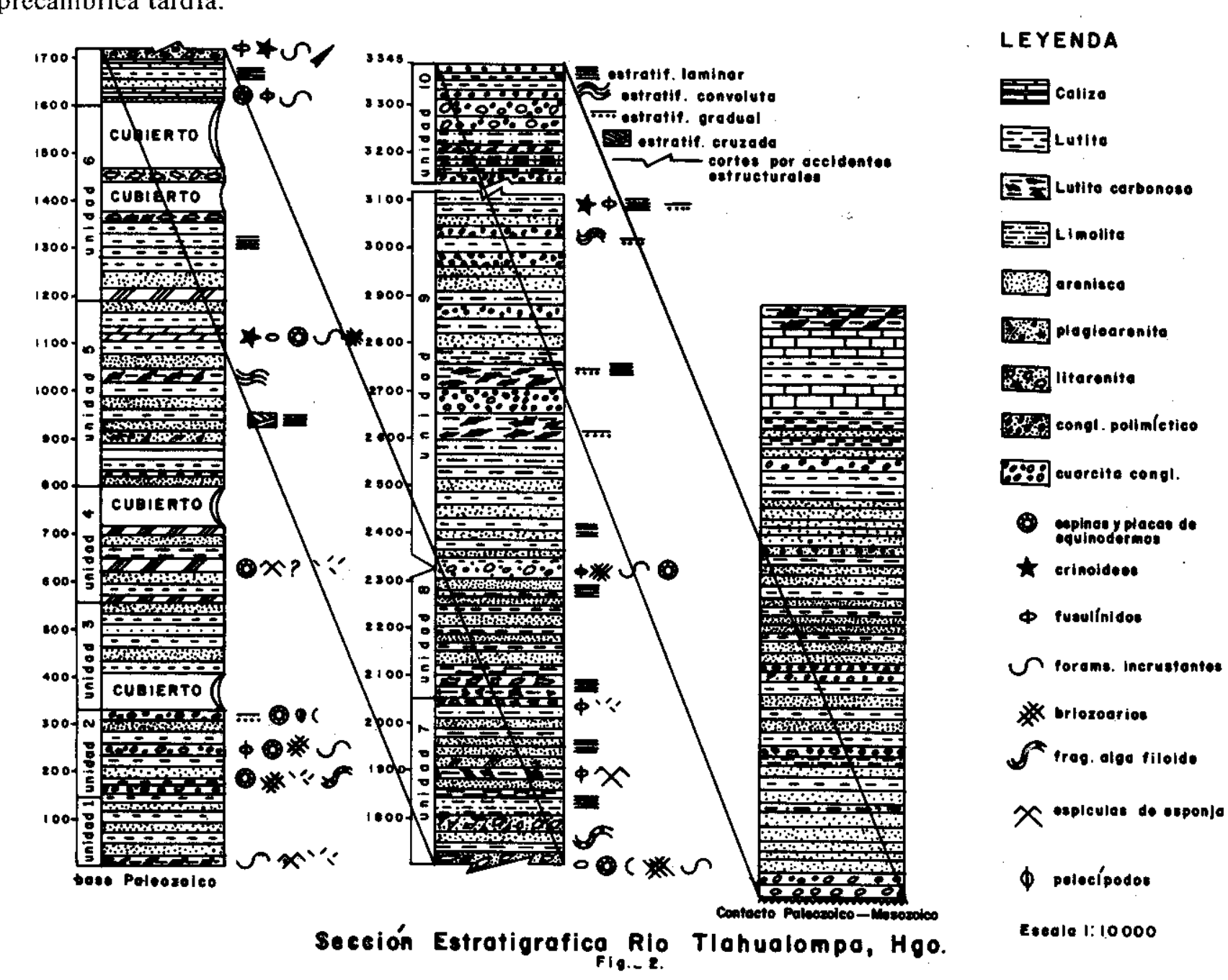

\section{DESCRIPCION DE LA COLUMNA}

En la sección del Rio Tlahualompa, la cima de la Formación Guacamaya (Fig. 2) se encuentra en contacto discordante con los sedimentos triásicos de la Formación Huizachal. El contacto PaleozoicoMesozoico se consideró de acuerdo a características únicamente litológicas y a los antecedentes del área (plano geológico de Carrillo, 1965); para un mejor control litológico estratigráfico de la columna se midió un espesor adicional de $1250 \mathrm{~m}$ arriba de lo que se consideró la cima del Paleozoico. La parte superior de esta sección está formada principalmente por lutitas carbonosas muy deleznables, en las que no se encontró fauna característica, tampoco se obtuvo resultado del análisis palinológico debido a la mala preservación de las muestras.

La base de la sección, la cual se encuentra en contacto por falla con rocas metamórficas de probable edad Precámbrico Tardío, se determinó tomando en cuenta los datos estructurales de campo y los datos previos de Carrillo (1965). 
La columna medida comprendió un espesor de $3345 \mathrm{~m}$, lo cual comparado por lo medido por Carrillo $(2000 \mathrm{~m})$, presenta una diferencia de 1345 $\mathrm{m}$, esto se debe a que la secuencia se encuentra plegada, por lo que existen algunas repeticiones en la columna.

Para una mejor interpretación litológica y posible correlación con otras secciones de la misma área, la sección Río Tlahualompa fué dividida en 10 unidades litológicas que se muestran en la fig. 2.

\section{LITOLOGIA}

La litología característica de la columna de rocas paleozoicas en el área está representada por una secuencia alternante, regular o irregular de lutitas con limolitas, areniscas, conglomerados y calizas.

Es notable en toda la columna la presencia constante de lutitas color oscuro, arcillo-carbonosas en espesores de 1 a $50 \mathrm{~cm}$, aunque a veces llegan a formar un metro o más de espesor. La mayor parte de ellas se encuentran silicificadas, sin fauna, con excepción de las muestras que presentan un abundante contenido fosilífero. En estas lutitas es común el material carbonoso muy fino $\mathrm{y} / \mathrm{o}$ en forma de pequeños fragmentos esparcidos esporádicamente o en finas laminaciones. A veces se observan cristales finos euhedrales de cuarzo y pirita distribuidos en la muestra. La materia carbonosa de este tipo de rocas fue considerada como materia orgánica muy alterada.

Otras muestras de origen detrítico, corresponden a limolitas $\mathrm{y}$ areniscas que se presentan formando capas con espesores que varían, los más delgados, de 1 a $5 \mathrm{~mm}$ pero, comúnmente de $5 \mathrm{~cm}$ hasta un metro, llegando a formar cuerpos muy potentes, principalmente en la parte media de la sección. De estas muestras, algunas veces se observó tanto en el campo como en lámina delgada, una estratificación laminar regular o irregular muy fina, alternando con capas carbonosas (Fig. 3). Otras muestran una ligera estratificación gradual y a veces cruzada. En lámina delgada se presentaron cambios bruscos en color y tamaño del grano (Lám. I, Fig. 1).

En las limolitas de grano fino y medio se observaron cristales de cuarzo angulosos y subangulosos, fragmentos carbonosos esparcidos o guardando una cierta orientación paralela, así como mica, feldespatos y fragmentos de calcita microcristalina, en ocasiones abundante y otras veces escasa.
Dentro del grupo de las areniscas se han observado litoarenitas y feldsarenitas; entre las litoarenitas, generalmente de mala clasificación, se logró observar una estratificación gradual y/o alternada en grano grueso y fino. El contenido mineralógico en este tipo de rocas está formado principalmente por feldespatos que incluyen tanto plagioclasas como ortoclasa, los cuales fueron observados como cristales bien formados y sin alteración; además, se observaron cristales angulosos y subangulosos de cuarzo, fragmentos ígneos y metamórficos, mal clasificados, dando lugar a un cierto grado de inmadurez textural; así como fragmentos de caliza, pirita y mica. La matriz está constituida por restos carbonosos, arcilla, clorita y algunas veces de calcita microcristalina.

En lo que se refiere a las feldsarenitas, algunas son ricas en plagioclasas, siempre completamente alteradas.

Los conglomerados en el área en estudio, llegan a formar grandes cuerpos masivos o estratos alternando con limolitas (Fig. 4); en algunos de ellos se observó una estratificación gradual, a veces irregular. La composición mineralógica en este tipo de rocas es semejante a la de las litoarenitas, variando sólo en proporción y tamaño de los fragmentos (de 225 micras a $3 \mathrm{~cm}$ de diámetro), siendo los componentes principales cuarzo, pedernal negro, fragmentos de roca y arcilla.

Se encontraron muy escasos afloramientos de caliza; se observaron calizas predominantemente de color oscuro y generalmente bioclásticas y silicificadas (op. $113,117,123,143$ y 144), a una proximidad de las Adjuntas, cerca de El Hormiguero y del poblado de Chapula.

También se observaron tres cuerpos ígneos (op. 85, op. 106 y op. 127) expuestos en dique, que intrusionan las lutitas o en forma de pequeños derrames andesíticos.

\section{BIOESTRATIGRAFIA}

En la tabla 1 se presenta la columna estratigráfica con la asociación faunística y litología característica de la sección Río Tlahualompa.

Aproximadamente 175 metros abajo, (estratigráficamente) después del contacto MesozoicoPaleozoico se observa la primera muestra con fauna paleozoica (op. 82) (Lám. 3, Fig. 6). Debido a la presencia de los fusulínidos (Triticites sp. y Schwagerina sp., así como foraminíferos incrustantes (calcivertélidos), la sección Río Tlahualompa fué 


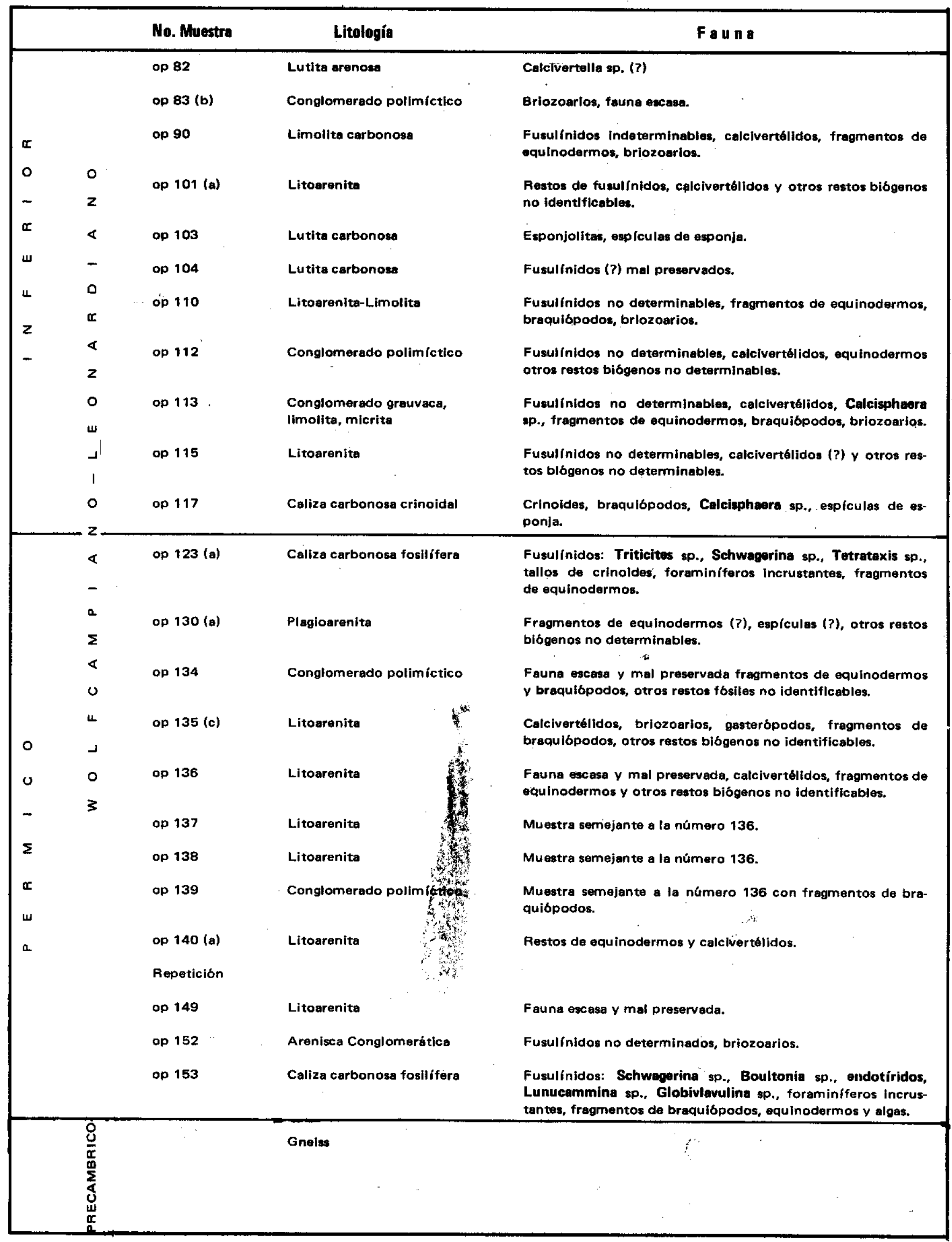




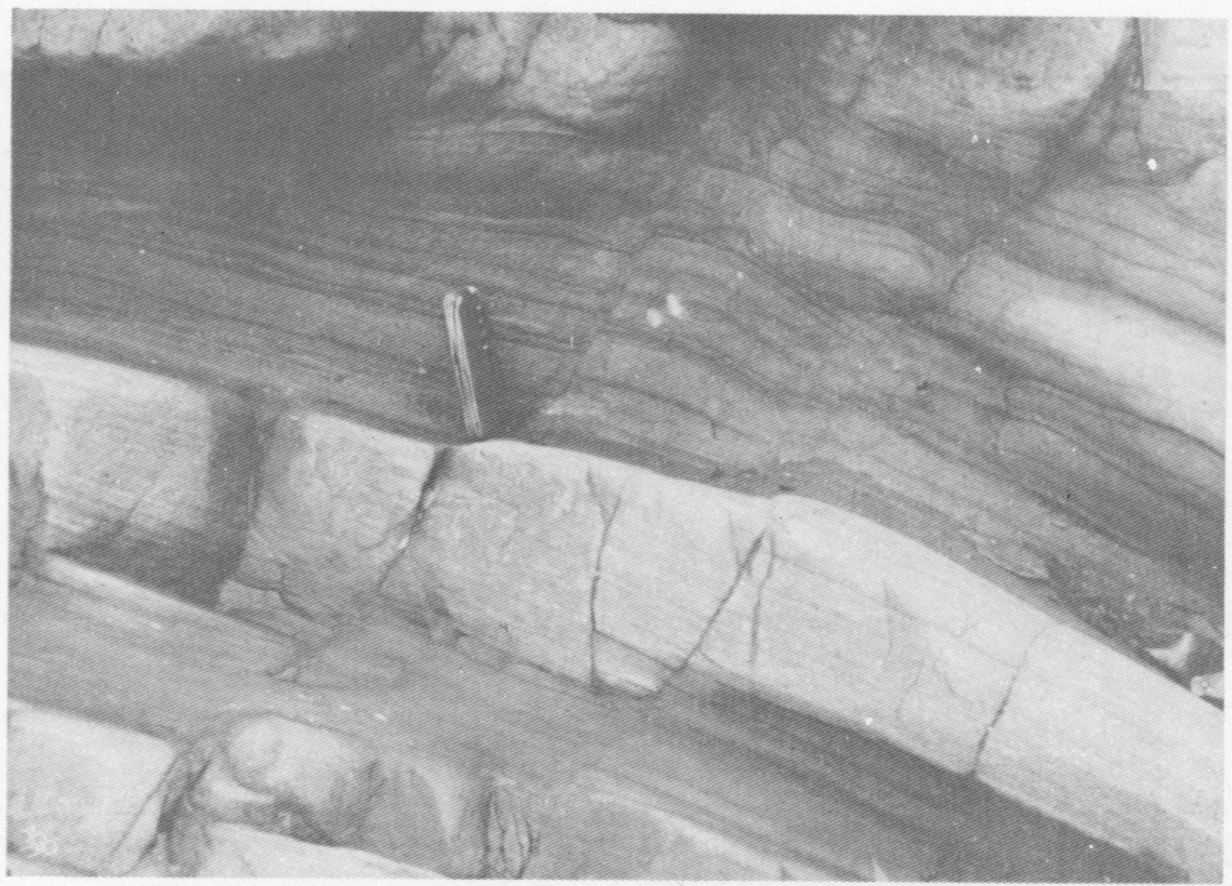

Fig. 3.- Secuencia lutita-limolita mostrando las finas laminaciones de materia orgánica carbonosa.

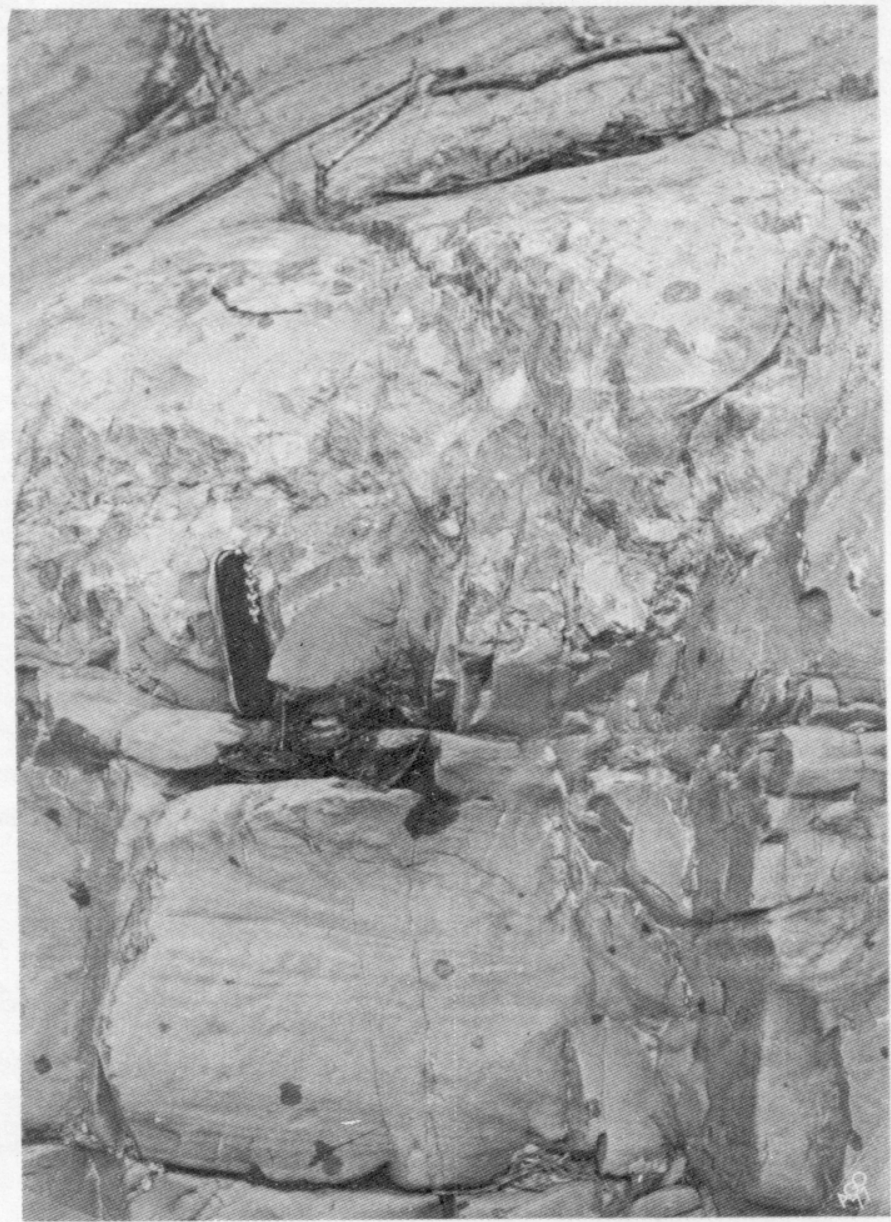

Fig. 4.- Conglomerado en alternancia con limolita, ésta última muestra finas laminaciones. 
situada estratigráficamente en el Paleozoico Superior, con edad del Pérmico Inferior (op. 123a, 153a) (Lám. 2, Figs. 1-5).

En general, en la cima y base de la columna se presenta fauna escasa y mal preservada; en la parte media, se observa un conjunto faunístico abundante y bien preservado.

\section{MICROFACIES Y TIPOS LITOLOGICOS TERRIGENOS}

Es importante aclarar que el término microfacies implica un conjunto litológico y paleontológico, sólo en rocas carbonatadas de acuerdo con la definición original de Cuvillier en 1952, por lo cual en este trabajo las microfacies que se agruparon se refieren únicamente a las rocas carbonatadas. Con respecto a las rocas detríticas, éstas sólo se distinguen como tipos litológicos.

De acuerdo con el estudio petrográfico y paleontológico de las calizas encontradas en la sección Río Tlahualompa, se distinguieron las siguientes microfacies:

1.- Micrita fosilífera. Se presenta una matriz micrítica con abundancia de foraminíferos incrustantes y fragmentos de algas, Calcisphaera $\mathrm{sp}$.; algunos fragmentos de braquiópodos (op. 113a) (Lám. 3, Fig. 2).

2.- Biomicrita (?) arcillosa fosilifera. Se presenta una matriz generalmente silicificada con remanentes de micritas arcillosa, con espículas de esponja, fusulínidos: Triticites sp., Schwagerna sp. y Boultonia sp. Endotíridos: Globivalvulina sp. y Lunucammina sp. Otros foraminiferos: Tetrataxis sp. y foraminíferos incrustantes. La fauna acompañante incluye fragmentos de braquiópodos, briozoarios, equinodermos y algas. La mayor parte de los restos fósiles están rellenos de calcita microcristalina (op. 117, 123a y 153) (Láms. 2 y 3). Son frecuentes finos cristales de pirita.

Entre los sedimentos terrígenos se presentan tres tipos litológicos: lutitas, areniscas y conglomerados.

Vale la pena mencionar que se encontró entre las lutitas un afloramiento de roca formado por abundantes espículas de esponja, con matriz silicificada (op. 103). Las areniscas así como los conglomerados se caracterizan por presentar una fauna escasa y mal preservada.

\section{PALEOECOLOGIA}

El conjunto faunístico observado en el área de estudio, en calizas y algunas lutitas calcáreas, está representado principalmente por: equinodermos (placas y espinas), crinoides (fragmentos y tallos), restos de gasterópodos, braquiópodos, briozoarios, espiculas de esponja y foraminiferos (Tetrataxis sp.), foraminíferos incrustantes (amodíscidos y calcivertélidos) y fusulínidos en diferentes estados de preservación, así como también Calcisphaera sp. y escasos fragmentos de algas filoides. Se encontraron afloramientos esporádicos de calizas con un contenido fosilífero abundante, principalmente marino somero, depositado en condiciones óptimas de luz, temperatura, oxígeno, salinidad, nutrientes y substrato adecuados para el desarrollo de organismos.

En los sedimentos terrígenos, hacia la cima y base de la columna, donde se observa fauna escasa y mal preservada, parece ser que no existieron las condiciones favorables para el desarrollo de organismos, considerándose dos posibilidades:

1.- Debido a una acumulación de material terrígeno grueso y diversificado, las condiciones mínimas ambientales fueron obstáculos para el desarrolo de fauna, lo que refleja su escasez.

2.- La fauna de origen somero es retrabajada y transportada por agentes físicos externos (corrientes de turbidez).

Es significativa la presencia constante en toda la columna de materia carbonosa depositada en finas laminaciones o en fragmentos que alternan con arcillas o limolitas. (en algunos casos cuarzosas, no fosiliferas y con ligera estratificación cruzada), reflejando cercanía a una área donde fué abundante la materia orgánica y la influencia periódica de limo y arena fina o arcilla acarreada por corrientes.

\section{Lámina 1}

Fig. 1.- Contacto limolita-lutita

Se observa una limolita con ligera estratificación cruzada. Finas fracturas atraviesan la estratificación. En la parte superior se observa la lutita carbonosa con fragmentos arcillosos. Impresión en acetato de la muestra op. 126. (2X).

\section{Fig. 2.- Biomicrita (?) silicificada.}

Con abundantes placas y espinas de quinodermo, principalmente crinoideos, rellenos de calcita microcristalina. Algunas espículas de esponja. Impresión en acetato de la muestra op. 117. (3X). 

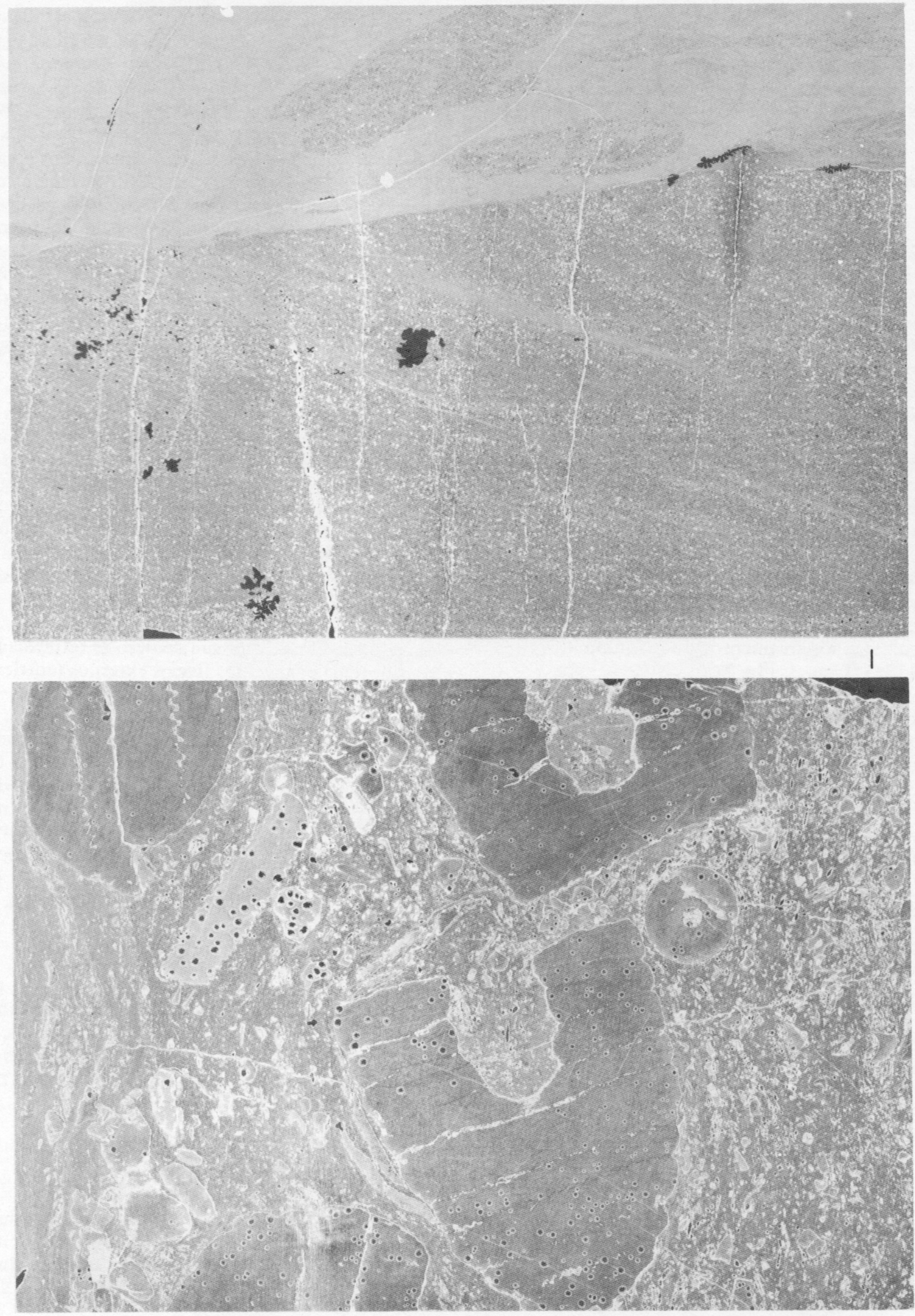


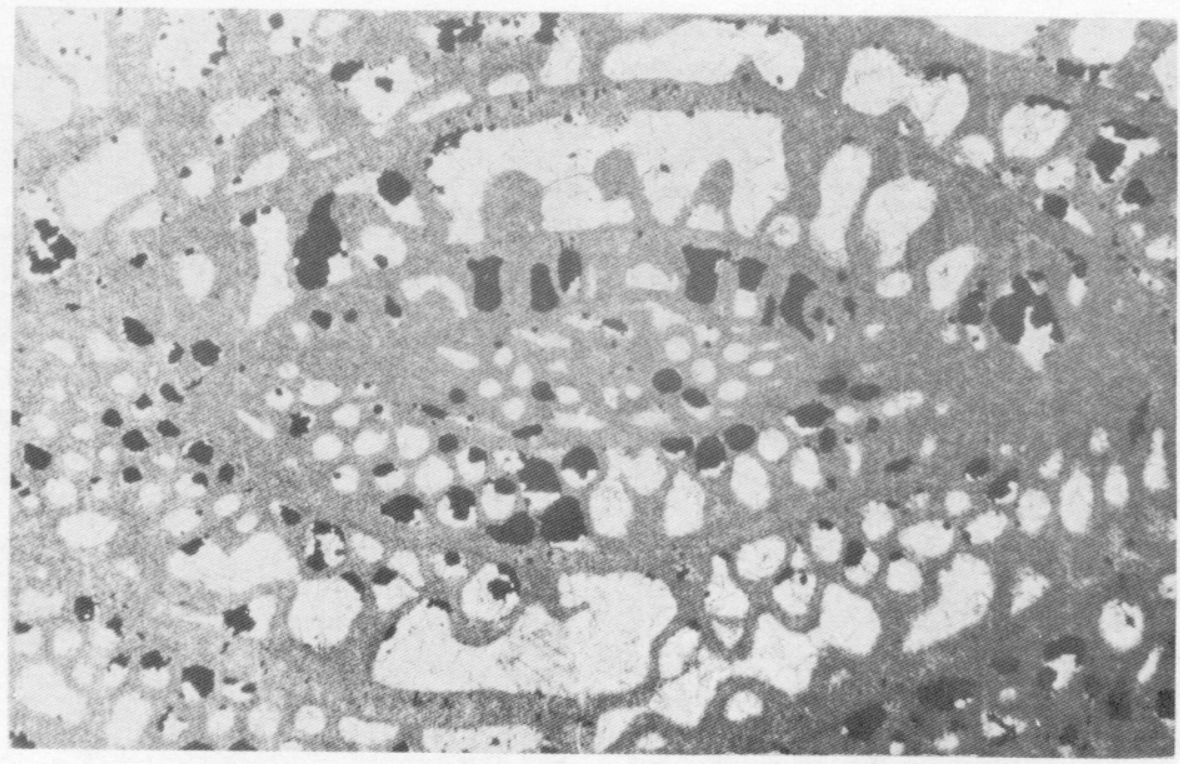

Fig. 1.- Tricites sp. (op. 123a) (X130)

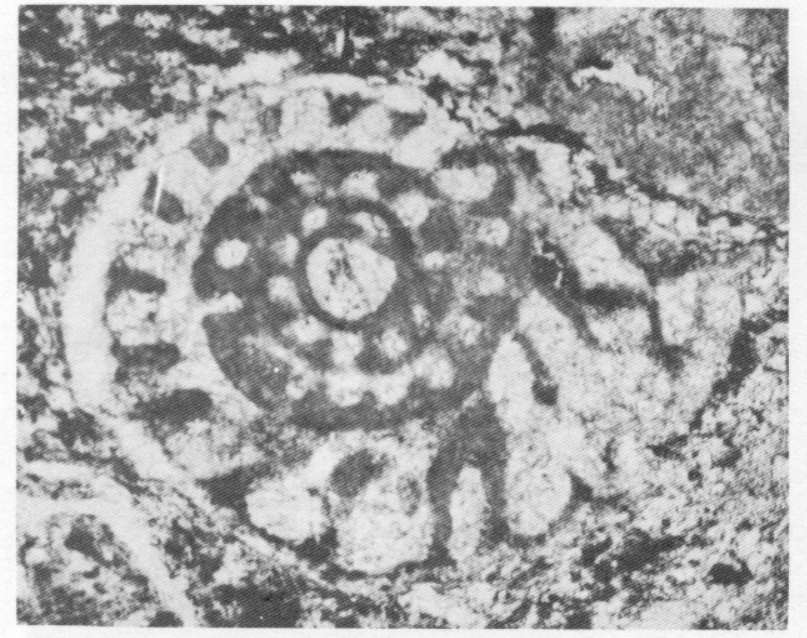

Fig. 2.- Fam. Schwagerinidae (op. 123a) (X140 y X30)

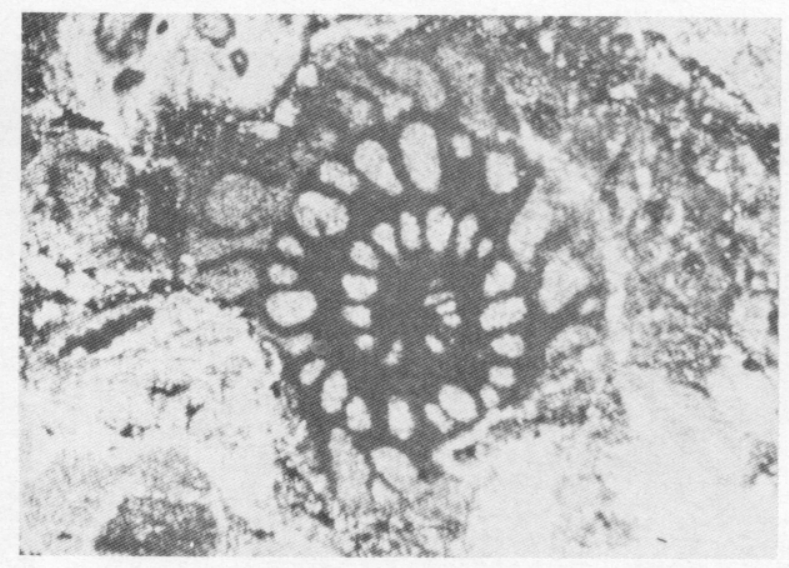

Fig. 3.- Corte transversal de fusulínido y fragmento de equinodermo (op. 113c) (X38).

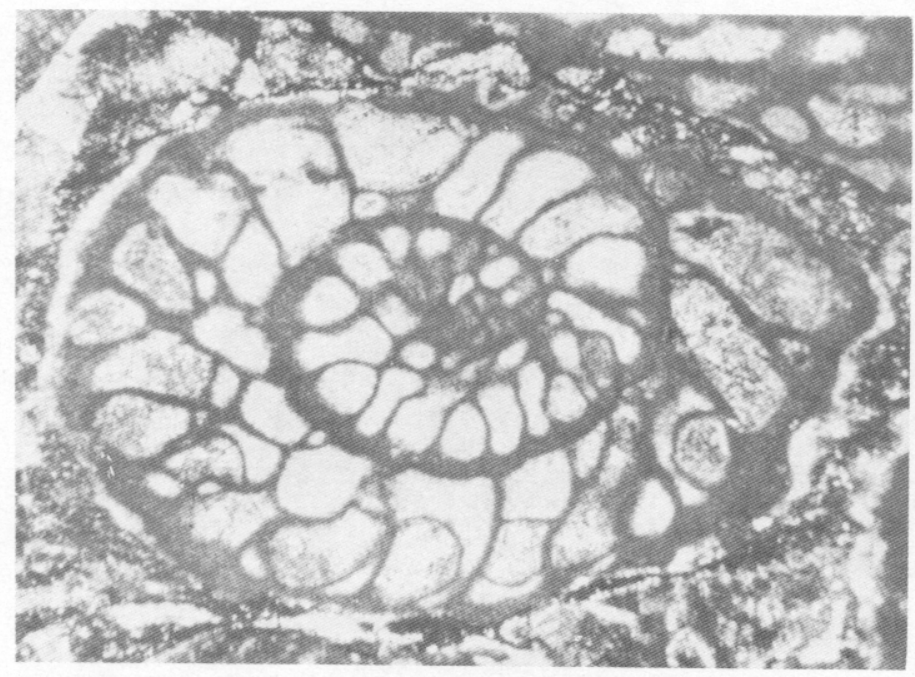

Fig. 4.- Fam. Schwagerinidae (op. 123a) (X140 y X30)

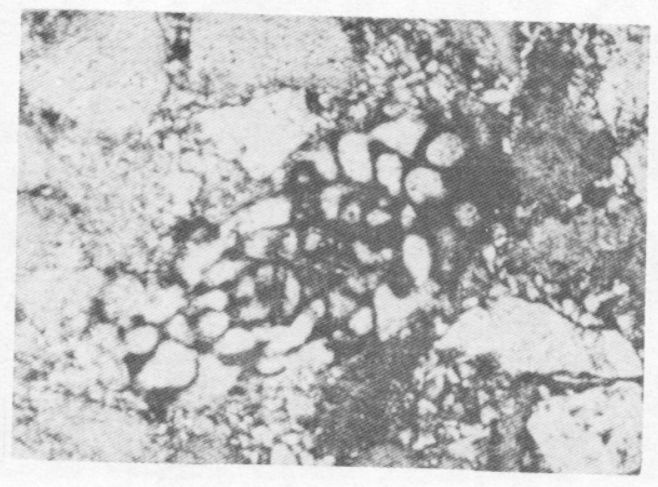




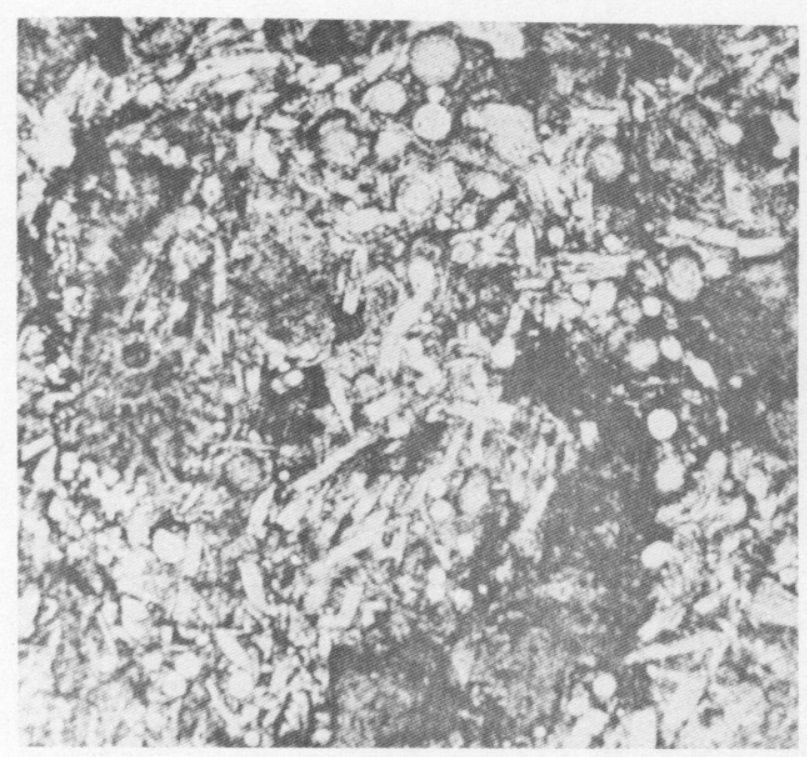

Fig. 1.- Biomicrita con espículas silicificadas en corte transversal y longitudinal (op. 117) (X35).

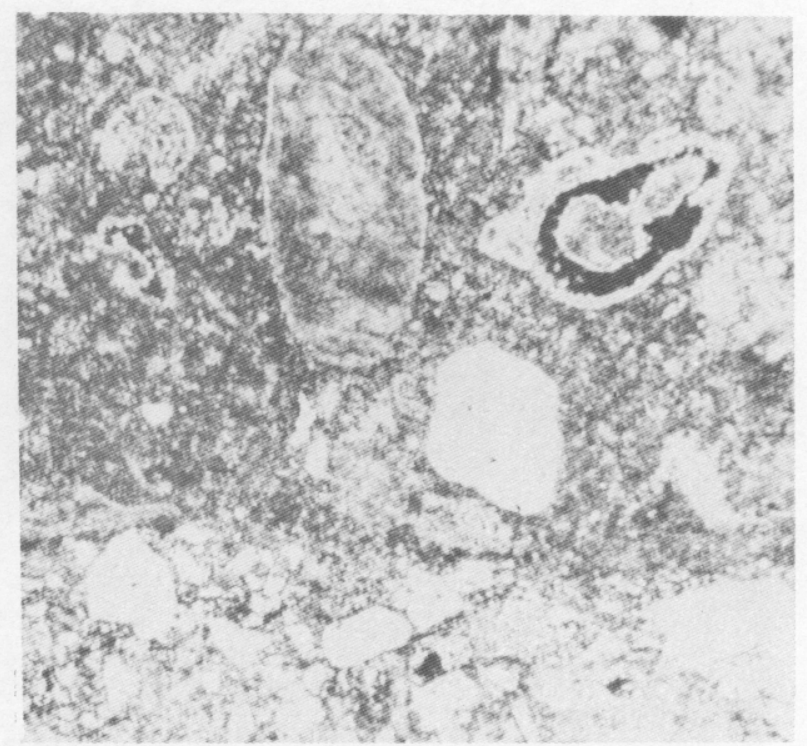

Fig. 2.- Contacto litoarenita-micrita con calcivertélidos (op. 113a) (X35).

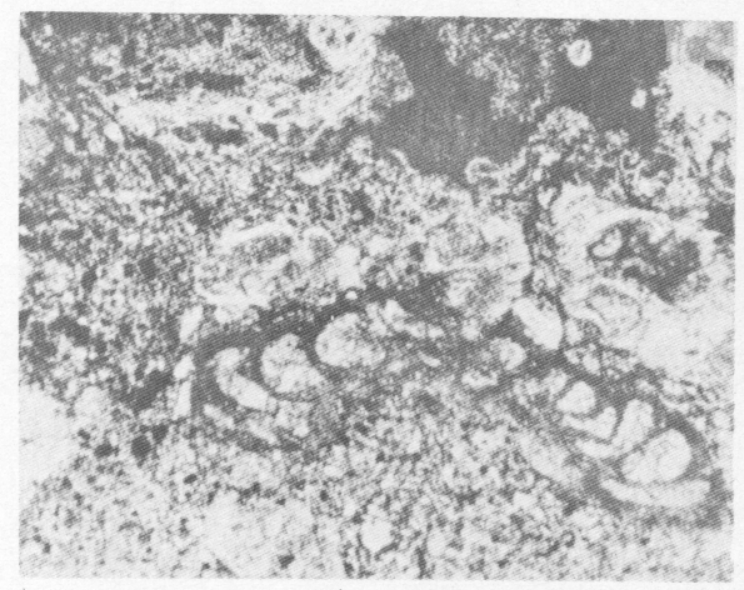

Fig. 3.- Foraminifero Tetrataxis sp. (op. 123a) (X37).

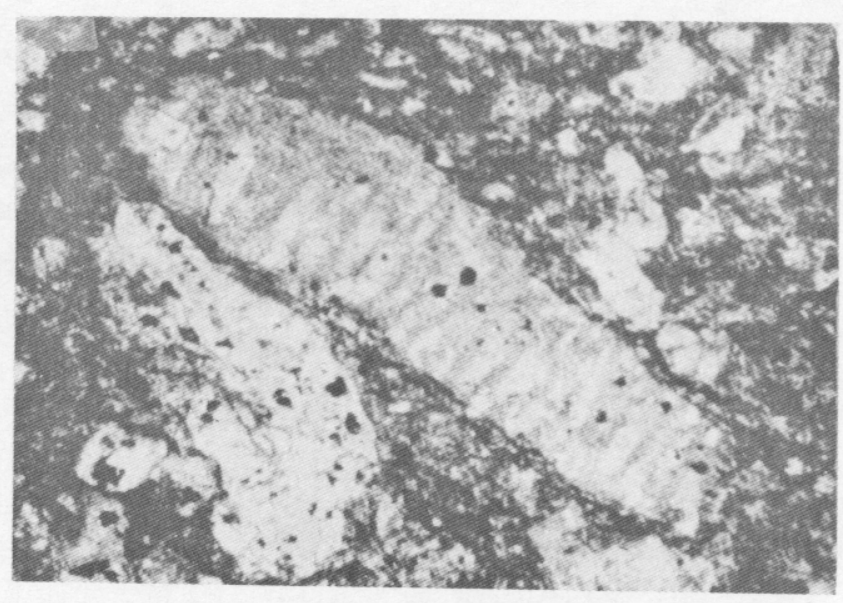

Fig. 4.- Alga filoide en micrita carbonosa (op. 153) (X70).

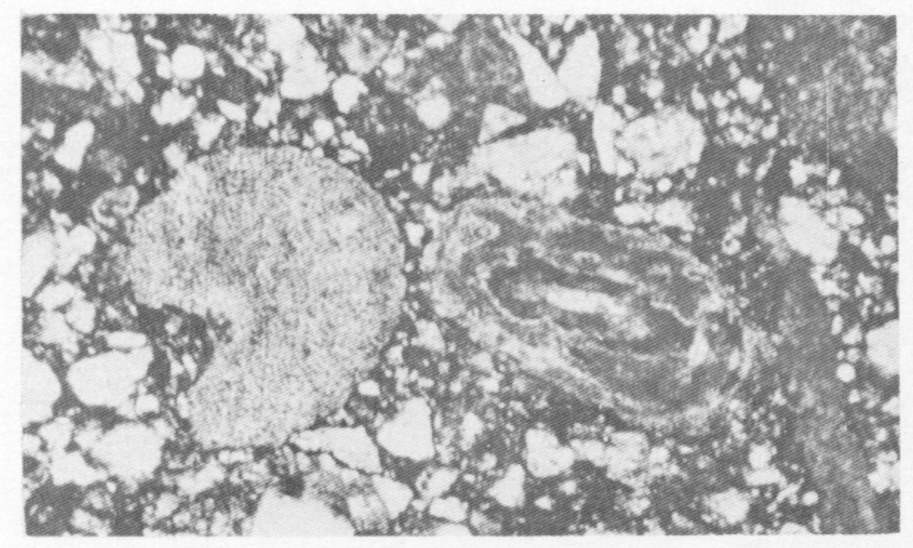

Fig. 5.- Calcivertélido y placa de equinodermo (op. 113b) (X30).

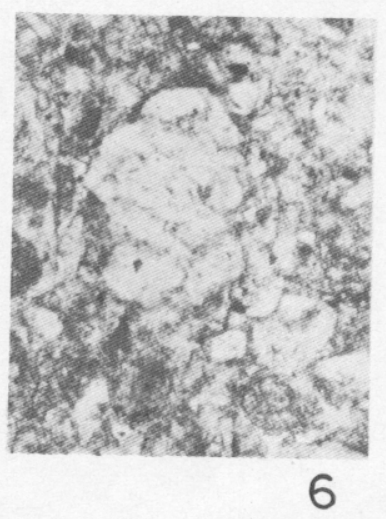

Fig. 6.- Calcivertella sp.

(?) (op. 82) (X65). 


\section{COMENTARIOS}

En la sección paleozoica del Río Tlahualompa fué notable el predominio de los terrígenos representados por una alternancia de lutitas y limolitas con areniscas (principalmente litoarenitas) y conglomerados. En estos dos últimos tipos de roca, parece ser hubo diferentes fuentes de origen, debido a la gran diversidad que presentan en sus componentes, incluyendo una fuente volcánica, por la relativa abundancia en fragmentos ígneos plagioclasas. Es notable también, la presencia aislada de calizas con abundante fauna marina.

De acuerdo a la litología y paleontología, se observaron cambios importantes en las condiciones de sedimentación. Se reflejan períodos de actividad tectónica en las grauvacas y conglomerados polimícticos, por la diversidad de componentes, mala clasificación y fauna marina retrabajada. Por otra parte los períodos de quietud se reflejan en las condiciones favorables para el depósito de carbonatos con fauna marina somera in situ. De acuerdo a las características de estas últimas, se infiere un depósito somero en condiciones marinas restringidas y reductoras (presencia de pirita y abundancia en materia orgánica).

Los terrígenos indican una aportación y sedimentación rápida de areniscas, seguida y/o alternada con un depósito de sedimentos finos. Estos caracteres acompañados de estructuras sedimentarias como estratificación gradual, escasa estratificación cruzada y erosión de las capas lutíticas hacen suponer un transporte por medio de corrientes de turbidez.

Sin embargo, estos caracteres están poco desarrollados, lo que puede ser el resultado de un transporte a baja velocidad sobre una plataforma de muy ligera pendiente.

Se interpreta esta secuencia considerando que en el mismo ambiente donde, en condiciones favorables, se formaron carbonatos, al variar las condiciones tectónicas regionales, se depositaron las potentes secuencias terrígenas observadas.

\section{REFERENCIAS BIBLIOGRAFICAS}

CARRILlo BRAVO, J.C., 1965. Estudio Geológico de una parte del Anticlinorio de Huayacocotla. Bol. Asoc. Mex. Geol. Petro., XVII, nos. 5-7, pp. 73-96.

CARRILlo BRAVO, J.C., 1961. Geología del Anticlinorlo Huizachal Peregrine at NW de Ciudad Victoria, Tamps. Bol. Asoc. Mex. Geol. Petro., V. XIII, nos 1-2, pp. 1-98.

CUVILLIER, J.. 1952. La notion de "microfacies" et ses applications, Convegno Naz Metano e Petrolio, Att. V. 1, pp. 149-153 itjust.

ERBEN, H.K., 1956. Estratigrafía à lo largo de la Carretera México D.F. y las áreas de Huachinango, Pue., Necaxa, Pue. y Huayacocotla, Ver., XX Congreso Geológico Internacional. México, Libreto-Gulas de la Excursión C-8, 1 Vol. pp. 9-54.

FRIES, C. Jr. Y RINCON-ORTA, C., 1965 Nuevas aportaciones geocronológicas y técnicas empleadas en el Laboratorio de Geocronometría, UNAM, Inst. de Geologla, Bol. 73, Pte. 2. $130 \mathrm{p}$.

MARTINEZ, P.M., 1962. Estudio Geológico de una porción de la Sierra Madre Oriental al Oriente de Zacualtipán y Tianguistengo, Hgo. ESIA, Tesis profesional pp. 47.

REYES, E.D., 1962. Identificación geológica de la Sierra Madre Oriental entre Tlanchinol y Zacualtipán, Hgo. Petróleos Mexicanos, Informe Geológico No. 500, pp. 44.

VOLLBRECHTSHAUSEN, U.R., 1963. Reconocimiento Geológico de una parte de la Sierra Madre Oriental entre el Rio Amajac y la carretera Pachuca-Huejutla, Hgo. Petróleos Mexicanos, Informe Geologico No. 502, pp. 54. 